\title{
Spatial distribution and determinants of an optimal ANC visit among pregnant women in Ethiopia: further analysis of 2016 Ethiopia demographic health survey
}

Zemenu Tadesse Tessema* (1) and Yaregal Animut

\begin{abstract}
Background: Antenatal care (ANC) is essential to improve maternal and newborn health and wellbeing. Antenatal care coverage is improving in Africa since over two-thirds of pregnant women have at least one ANC contact. However, to realize the complete life-saving potential that ANC guarantees for mothers and babies, at least four visits providing essential evidence-based interventions are required.. Therefore, this study was conducted to identify determinants of an optimal ANC visit and its spatial distribution in Ethiopia.

Methods: This study is a secondary data analysis of the 2016 Ethiopian Demographic and Health Survey (EDHS). A total of 8025 women who had a live birth in the five years preceding the survey were included in this study. STATA 14 software and ArCGIS10.7 software were used for analysis. The generalized estimating equation (GEE) model was fitted to identify factors associated with an optimal ANC visit. Crude and Adjusted odds ratio with a 95\% Cl computed to assess the strength of association between explanatory and outcome variables.

Results: This study revealed that rural residence (AOR $=0.59,95 \% \mathrm{Cl}: 0.45-0.77)$, male partners educational status [secondary school ( $\mathrm{AOR}=1.33,95 \% \mathrm{Cl}: 1.05-1.67)$ ], distance to the health institutions [not a big problem $(\mathrm{AOR}=1.21$, 95\%Cl: 1.04-1.39)], community-level literacy ( $\mathrm{AOR}=1.07,95 \% \mathrm{Cl}: 1.03-1.12)$, and community level service utilization $(A O R=2.67,95 \% C l: 2.21-3.24)$ were significantly associated with optimal ANC visits. From the spatial analysis result, an Optimal ANC visit was observed in Addis Ababa, Tigray, Harari, and Dire Dawa regions whereas areas with no optimal ANC visit were Afar, Amhara, Oromia Benishangul, SNNP, and Somalia regions.

Conclusion: Living in peripheral regions of the country and in rural areas, lower educational status of male partners and distance to health institutions were prohibiting factors for an adequate number of visits. In this study, community-level literacy and community level service utilizations were were also affect womens' ANC utilization which implies community-level interventions should be considered for improving antenatal care utilization and better health outcomes. The government should give special attention to the regions like Afar, Amhara, Oromia, Benishangul, SNNP, and Somalia which had low optimal ANC visits.
\end{abstract}

Keywords: Optimal antenatal care visit, Determinant, Spatial distribution, Ethiopia

\footnotetext{
* Correspondence: zemenut1979@gamil.com

Department of Epidemiology and Biostatistics, Institute of Public Health,

College of Medicine and Health Sciences, University of Gondar, Gondar,

Ethiopia
}

(c) The Author(s). 2020 Open Access This article is distributed under the terms of the Creative Commons Attribution 4.0 International License (http://creativecommons.org/licenses/by/4.0/), which permits unrestricted use, distribution, and reproduction in any medium, provided you give appropriate credit to the original author(s) and the source, provide a link to the Creative Commons license, and indicate if changes were made. The Creative Commons Public Domain Dedication waiver (http://creativecommons.org/publicdomain/zero/1.0/) applies to the data made available in this article, unless otherwise stated. 


\section{Background}

An estimated 303,000 women around the world died due to complications of pregnancy and childbirth in 2015. The risk of death is disproportionately high among women living in sub-Saharan Africa, yet most maternal deaths suffered each year are preventable [1]. Antenatal care utilization has acknowledged benefits in reducing maternal and fetal mortality by delivering effective and appropriate screening, preventive, or treatment interventions $[2,3]$. ANC services in low-income and middleincome countries result in significant improvement in birth outcomes and long-term reductions of child mortality and malnourishment [4].

WHO recommends eight ANC contacts, although many African countries including Ethiopia are still struggling to achieve high coverage of four ANC visits [5]. Ethiopia is still using the previous recommendation of 4 ANC visit to declare a woman for having an optimal ANC visit. Each visit should consist of care that is necessary to the overall condition and stage of pregnancy and should include four main categories of care that include: identification of pre-existing health conditions, early detection of complications arising during pregnancy, health promotion and disease prevention, and birth preparedness and complication planning [6].

Other evidence also showed that attending three or fewer ANC visits in uncomplicated pregnancies is associated with increased perinatal mortality in low- and middle-income countries as compared to the recommended number of visits $[7,8]$. However, only half of women worldwide receive the recommended amount of care during pregnancy. Overall $86 \%$ of pregnant women access antenatal care with skilled health personnel at least once, only three in five (62\%) receive at least four antenatal visits. In places with the highest rates of maternal mortality, such as sub-Saharan Africa and South Asia, even fewer women received at least four antenatal visits (52 and 46\%, respectively) [9].

Despite many efforts of the government high maternal mortality (412/100000 live births) was reported in the 2016 Ethiopian Demographic and Health Survey (EDHS). The Ethiopian government targets to reduce maternal mortality to $199 / 100000$ live births in its Health Sector Transformation Plan (2015/16-2019/20) and one of the strategies is achieving 95\% ANC utilization of at least 4 visits. Only $32 \%$ of pregnant women had 4 ANC visits with regional variations. In order to fill this gap, it is necessary to conduct researches to identify the determinants for optimal ANC visits and its spatial distribution. There is a scarcity of national data on spatial distribution and factors associated with optimal ANC visits, Therefore, the aim of this study was to assess factors associated with optimal ANC utilization and its spatial distribution using nationwide data from the Ethiopian Health and Demographic Survey 2016.

\section{Methods}

\section{Study design and study settings}

A cross-sectional study design was employed using the Ethiopian Demography and Health Surveys (EDHS) 2016. Ethiopia is located in the horn of Africa. It has a total area of $1,100,000 \mathrm{~km} 2$ and lies between latitudes $3^{\circ}$ and $15^{\circ} \mathrm{N}$, and longitudes $33^{\circ}$ and $48^{\circ} \mathrm{E}$. Based on the 2007 population and housing census projection, Ethiopia has a population size of $112,078,730$ with $23.4 \%$ (26,226, 422) of them were under reproductive age group women [10]. Ethiopia has been divided into nine ethnic-based and politically autonomous regional states (Afar, Amhara, Benishangul Gumuz, Gambela, Harari, Oromia, Somali, Southern Nations, Nationalities, and People's Region (SNNP) and Tigray) and two cities (Addis Ababa and Dire Dawa (Fig. 1).

\section{Data source}

This study is a secondary data analysis from the 2016 Ethiopia Demographic and Health Survey which was collected cross-sectionally from January 2015 to June 2015.

\section{Population and sample}

All pregnant women five years preceding the survey were the study population. We used individual record (IR) files to extract the study participants of this study. The EDHS used a stratified two-stage sampling technique to select the final study participant women. Initially, the enumeration areas were stratified into urban and rural of which, 202 and 443 enumeration areas were selected from urban and rural, respectively using a probability method based on proportional to the size of Enumiration Areas (EA) and with an independent selection in each sampling stratum. In this study 622 EAs were used for spatial analysis. In EDHS 2016 a total of 16,583 eligible women were identified for individual interviews. Interviews were completed with 15,683 women, yielding a response rate of 95\%.. Among 15,683 interviewed women only 8025 who had live birth in the five years preceding the survey were included in this study. For those women who had two live birth in the five years preceding the survey, only recent birth was taken. The detail of the methodology is available in the full report of 2016 EDHS [11].

\section{Data and variables}

The Ethiopian Demographic and Health Survey (EDHS, 2016) data set was used for this analysis). The study population consists of women age 15-49 years and pregnant women five years preceding the survey. Out of 8025 women who had a live birth in the five years preceding the survey, only 2499 women had an optimal ANC visits. The binary response variable considered in this study indicated if a women completed an optimal 


\section{The Map of Ethiopa}

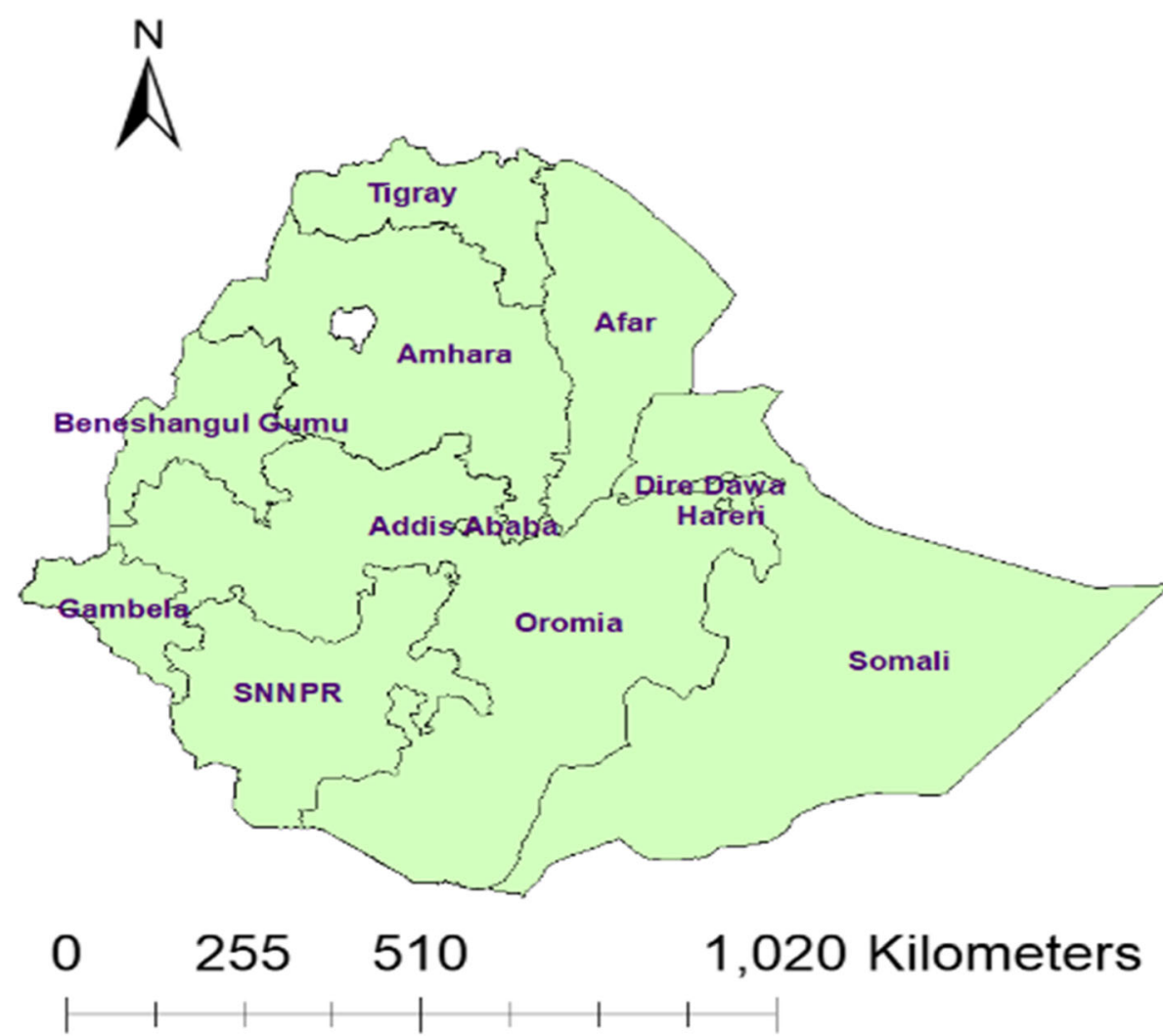

Fig. 1 Study area of 9 regions and two city administrations in Ethiopia .(Source: Shape file from Ethiopia Central Statistical Agency (CSA), 2013 at https://africaopendata.org/dataset/ethiopia-shapefiles)

ANC visits from skilled health care provider (Doctors, Midwives, Nurses, and Health officers) coded as 1 and 0 otherwise. Potential explanatory variables associated with completing an optimal ANC visits were based on related studies conducted on the factors influencing ANC utilization. Explanatory variables like current age, education status of women and husband, parity, marital status, sex of the household head, birth order, timing of ANC, distance to health facility and wealth index were used at individual level and residence, region, community-level ANC utilization and community level media exposure were used as community level variables.

\section{Spatial analysis}

\section{Spatial autocorrelation analysis}

The spatial autocorrelation (Global Moran's I) statistic measures whether optimal ANC utilization patterns were dispersed, clustered or randomly distributed in the study area [1]. Moran's I is a spatial statistics used to evaluate spatial autocorrelation considering data set and produce a single output value which ranges from -1 to +1 . Moran's I Values close to -1 indicate disease dispersed, whereas I close to +1 indicate disease clustered and disease distributed randomly if I value is zero. A statistically significant Moran's I $(p<0.05)$ leads to rejection of the null hypothesis (home delivery is randomly distributed) and indicates the presence of spatial autocorrelation.

\section{Incremental autocorrelation}

These peak distances are often appropriate values to use for tools with a Distance Band or Distance Radius parameter. This tool can help you select an appropriate Distance Threshold or Radius for tools that have these parameters, such as hot spot analysis [1].

\section{Hot spot analysis (Getis-OrdGi* statistic)}

Getis-OrdGi* statistics was computed to measure how spatial autocorrelation varies over the study location by calculating $\mathrm{GI}^{*}$ statistic for each area. Z-score was computed to determine the statistical significance of clustering, and the $p$-value computed for the significance. The statistical result with high $\mathrm{GI}^{*}$ indicates "hotspot" whereas low GI* means a "cold spot". 
Table 1 Distribution of an optimal antenatal care visit by categories of selected variables among women's in Ethiopia, 2016

\begin{tabular}{|c|c|c|}
\hline Variables & Count (\%) & $\%$ of 4 or more ANC visit (optimal) \\
\hline \multicolumn{3}{|c|}{ An optimal completion of ANC visit } \\
\hline No & $5526(68.86)$ & \\
\hline Yes & $2499(31.14)$ & 100 \\
\hline \multicolumn{3}{|l|}{ Marital status } \\
\hline Never in union & $7656(95.4)$ & 30.88 \\
\hline Currently in union & $369(4.60)$ & 36.52 \\
\hline \multicolumn{3}{|l|}{ Sex of household headed } \\
\hline Male & $6870(85.60)$ & 30.02 \\
\hline Female & $1155(14.40)$ & 37.79 \\
\hline \multicolumn{3}{|l|}{ Place of Residence } \\
\hline Urban & $968(12.07)$ & 62.95 \\
\hline Rural & $7057(87.93)$ & 26.77 \\
\hline \multicolumn{3}{|l|}{ Age } \\
\hline $15-19$ & $260(3.24)$ & 28.60 \\
\hline $20-24$ & $1500(18.69)$ & 30.61 \\
\hline $25-29$ & $2503(31.19)$ & 32.58 \\
\hline $30-34$ & $1795(22.37)$ & 31.40 \\
\hline $35-39$ & $1322(16.47)$ & 32.01 \\
\hline $40-44$ & $447(5.56)$ & 25.45 \\
\hline $45-49$ & $199(2.48)$ & 25.02 \\
\hline \multicolumn{3}{|l|}{ Birth order } \\
\hline 1 & $1632(20.33)$ & 39.42 \\
\hline $2-4$ & $3399(42.35)$ & 32.15 \\
\hline$>=5$ & $2995(37.32)$ & 25.48 \\
\hline \multicolumn{3}{|l|}{ Women Level of education } \\
\hline Unable to read and write & $5203(64.83)$ & 25.71 \\
\hline Primary education & $2198(27.38)$ & 36.04 \\
\hline Secondary education & $414(5.16)$ & 58.04 \\
\hline Higher education & $211(2.63)$ & 60.67 \\
\hline \multicolumn{3}{|c|}{ Husband level of education $(n=7578)$} \\
\hline Unable to read and write & $3761(49.64)$ & 25.06 \\
\hline Primary education & $2878(37.98)$ & 31.77 \\
\hline Secondary education & $598(7.89)$ & 50.03 \\
\hline Higher education & $341(4.49)$ & 53.04 \\
\hline \multicolumn{3}{|l|}{ Wealth quartile } \\
\hline Poor & $3649(45.47)$ & 22.74 \\
\hline middle & $1613(20.10)$ & 29.25 \\
\hline rich & $2763(34.43)$ & 43.21 \\
\hline \multicolumn{3}{|l|}{ Parity } \\
\hline 1 & $2145(30.54)$ & 38.55 \\
\hline $2-5$ & $3095(38.57)$ & 37.13 \\
\hline$>5$ & $2479(30.89)$ & 24.32 \\
\hline \multicolumn{3}{|l|}{ Distance to health facility } \\
\hline Big problem & $4823(60.10)$ & 46.76 \\
\hline Not big problem & $3202(39.90)$ & 54.24 \\
\hline
\end{tabular}

Media Exposure 
Table 1 Distribution of an optimal antenatal care visit by categories of selected variables among women's in Ethiopia, 2016 (Continued)

\begin{tabular}{|c|c|c|}
\hline Variables & Count (\%) & $\%$ of 4 or more ANC visit (optimal) \\
\hline Exposure & $5399(68.24)$ & 58.03 \\
\hline Non Exposed & $2513(31.76)$ & 41.97 \\
\hline \multicolumn{3}{|l|}{ Region } \\
\hline Tigray & $532(6.63)$ & 57.10 \\
\hline Afar & $78(0.97)$ & 19.99 \\
\hline Amhara & $1671(20.83)$ & 30.73 \\
\hline Oromia & $3436(42.82)$ & 22.22 \\
\hline Somalia & $322(4.01)$ & 10.43 \\
\hline Benishangul Gumuz & $88(1.10)$ & 41.52 \\
\hline SNNP & $1623(20.33)$ & 38.09 \\
\hline Gambela & $22(0.27)$ & 41.53 \\
\hline Harari & $19(0.24)$ & 32.54 \\
\hline Addis Ababa & $198(2.47)$ & 89.08 \\
\hline Dire Dawa & $34(0.43)$ & 64.32 \\
\hline \multicolumn{3}{|l|}{ Community level ANC } \\
\hline low & $2776(32.09)$ & 19.86 \\
\hline high & $5450(67.91)$ & 55.00 \\
\hline \multicolumn{3}{|l|}{ Community level literacy } \\
\hline low & $3524(43.91)$ & 39.64 \\
\hline high & $4502(56.09)$ & 24.48 \\
\hline \multicolumn{3}{|l|}{ Timing of ANC } \\
\hline Less than 12 weeks & $1092(13.61)$ & 23.29 \\
\hline More than 12 weeks & $6933(86.39)$ & 76.71 \\
\hline
\end{tabular}

\section{Spatial scan statistical analysis}

A Bernoulli-based model was used in which events at particular places were analyzed if women had an optimal ANC visit or not represented by a $1 / 0$ variable. The scan statistics developed by Kulldorff and SaTScan ${ }^{\mathrm{Tm}}$ software version 9.6 were used to identify the presence of purely spatial home delivery clusters.

\section{Spatial interpolation}

It is very expensive and laborious to collect reliable data in all areas of the country to know the burden of certain events. Therefore, part of a certain area can be predicted by using observed data using a method called interpolation. The spatial interpolation technique was used to predict stillbirth on the un-sampled areas in the country based on sampled EAs. There are various deterministic and geostatistical interpolation methods. Among all of the methods, ordinary Kriging and empirical Bayesian Kriging was considered the best method since it incorporates the spatial autocorrelation and it statistically optimizes the weight.. For this study, the ordinary Kriging method was used to estimate an optimal ANC visit in unsampled areas.

\section{Statistical analysis}

Data processing and analysis

STATA 14.1 software used for the whole analysis of this study. Summary measures such as median with IQR, frequencies with percentages computed; tables, figures, and text used to present the results. We checked for the presence of correlation among observations within clusters (enumeration areas) and the result showed that there was a within-cluster correlation, which indicated that there is a correlation among observations at the cluster level. The generalized estimating equation (GEE) model was fitted to identify factors associated with determinants for optimal ANC visit among reproductiveage women. The generalized estimating equation was fitted with logit link function, binomial family and working correlation structures (independent, exchangeable, unstructured, and autoregressive) were compared for the smallest standard error difference of robust and model-based standard error. Finally, the exchangeable correlation was selected for this study to handle within correlation. Crude and adjusted odds ratio with a 95\% CI computed to assess the strength of association between independent and outcome variable. 


\section{Results}

\section{Characteristics of the sample}

Among the 8025 sampled women, only 31\% (95\% CI 29.5-33.5) had an optimal ANC visit. Out of the total women considered for this study, 69\% had at least one ANC visit and $37.4 \%$ visit in third trimester. The results also showed that $7057(87 \%)$ were rural residents. Only $26.77 \%$ of rural respondents complete four or more ANC visits, while $62.95 \%$ of urban residents completed the recommended four or more ANC visits (Table 1).

\section{Spatial analysis results}

\section{Spatial autocorrelation}

The spatial autocorrelaton results revealed that an optimal ANC visits had clustering effct in Ethiopia (means in some areas there was high an Optimal ANC visits and in Some areas there were low an Optimal ANC visits). The outputs have automatically generated keys on the right and left sides of each panel. The $\mathrm{z}$ score of 26.94 indicated that there is less than $1 \%$ likelihood that this clustered pattern could be the result of random chance. The bright red and blue colors to the end tails indicate an increased significance level. The table shows that the observed value is greater than the expected value and $P$-value is $<0.05$, thus it is statistically significant and means that there is spatial variability in optimal utilization of ANC among pregnant women in Ethiopia. (Fig. 2).
Spatial distribution of subjects who completed the optimal number of ANC visits in Ethiopia

A total of 622 clusters were considered for the spatial analysis of an optimal ANC visit. Each point on the map represents one enumeration area with a proportion of an Optimal ANC visit in each cluster. The red color indicates areas with a high proportion of optimal ANC whereas blue color indicates EAs with lower proportion an optimal ANC visit (Fig. 3).

\section{Incremental autocorrelation}

Incremental spatial autocorrelation for a series of distance presented by a line graph. A corresponding Z-score was done to determine the average nearest neighbor, minimum, and maximum distance band. Totally 10 distance bands were detected by a beginning distance of 121,803 $\mathrm{m}$, and first maximum peak (clustering) was observed at 151379.64 m (Fig. 4).

\section{Hot spot analysis of optimal ANC visit in Ethiopia}

The red color indicates that significant areas to have an optimal ANC visit. This is found in Addis Ababa, Tigray region, Harari and Diredawa whereas, the blue color indicates significant areas that had no optimal ANC visit observed in the Somalia region, Amhara region, Afar Region, Oromia region and Gambella region (Fig. 5).

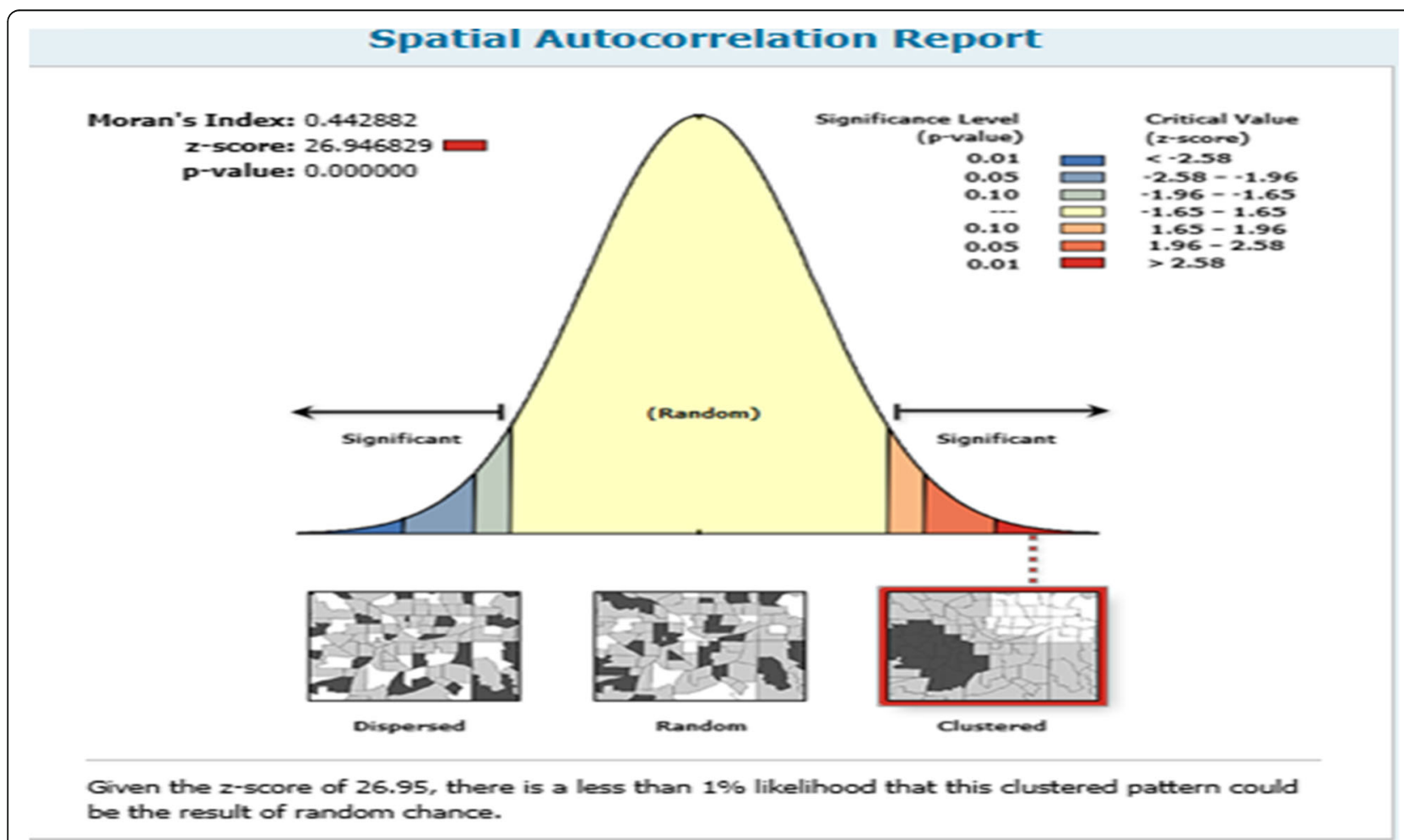

Fig. 2 Spatial autocorrelation of an Optimal ANC visit in Ethiopia across regions (Source: Shape file from Ethiopia Central Statistical Agency (CSA), 2013https://africaopendata.org/dataset/ethiopia-shapefiles) 

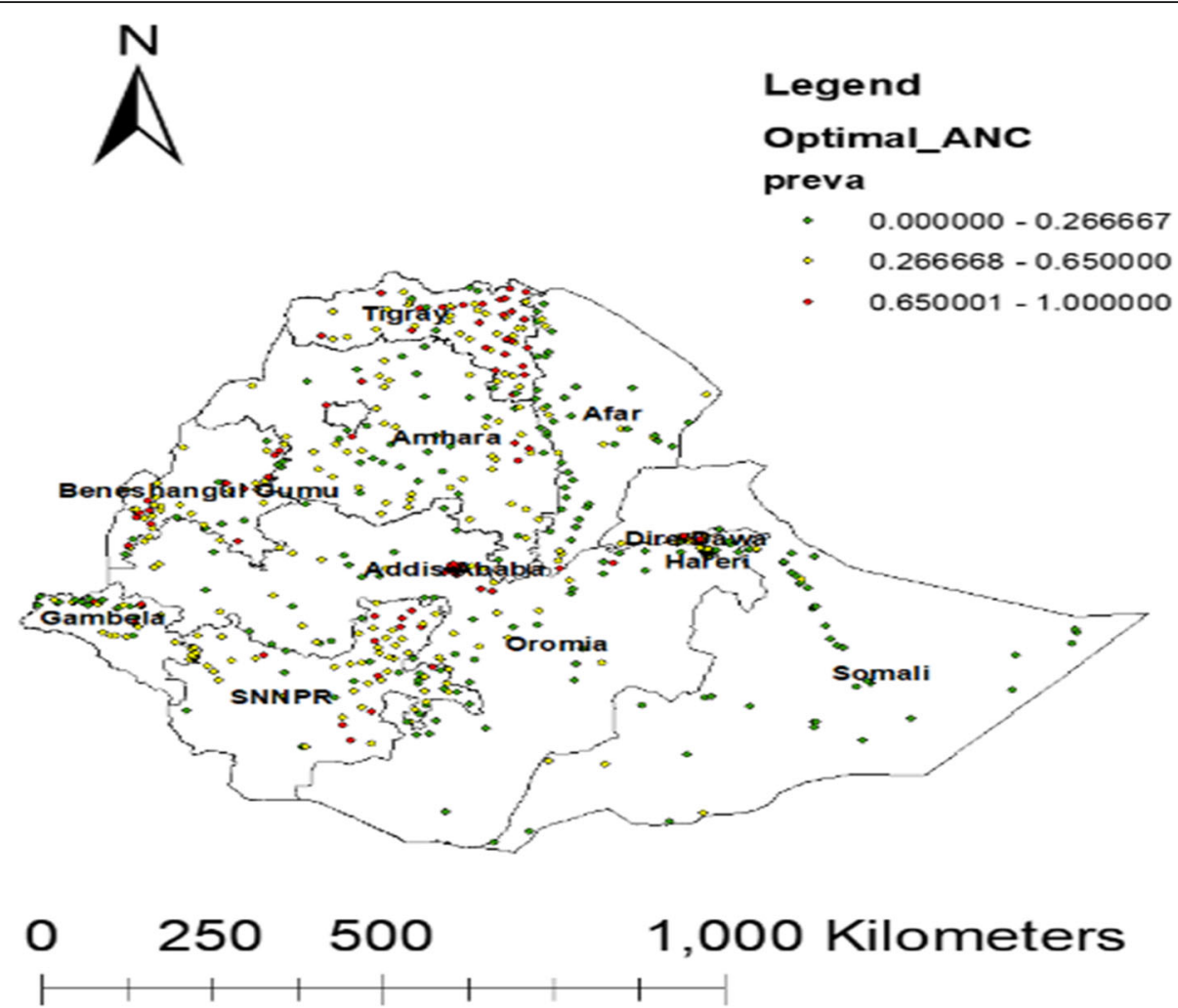

Fig. 3 Spatial distribution of an optimal ANC visit across the (Source: Shape file from Ethiopia Central Statistical Agency (CSA), 2013 https://africaopendata.org/dataset/ethiopia-shapefiles)

\section{Interpolation of an ANC visit}

The interpolated spatial analysis result predicted the unsampled areas. The red color indicates the predicted not had an Optimal ANC visit and the green color indicates the predicted high optimal ANC visit areas. The map indicated that Afar, Somali, and Gambella are regions which had low optimal ANC visits (Fig. 6).

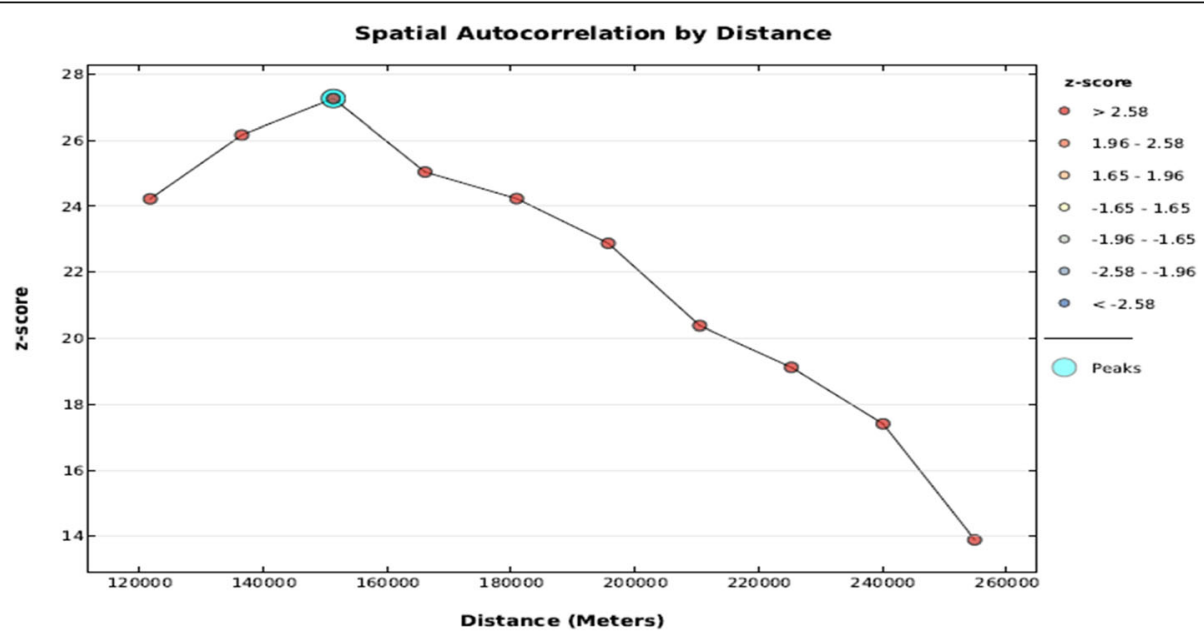

Fig. 4 Incremental autocorrelation of optimal ANC utilization among pregnant women in Ethiopia,2016 (Source: Shape file from Ethiopia Central Statistical Agency (CSA), 2013 https://africaopendata.org/dataset/ethiopia-shapefiles) 


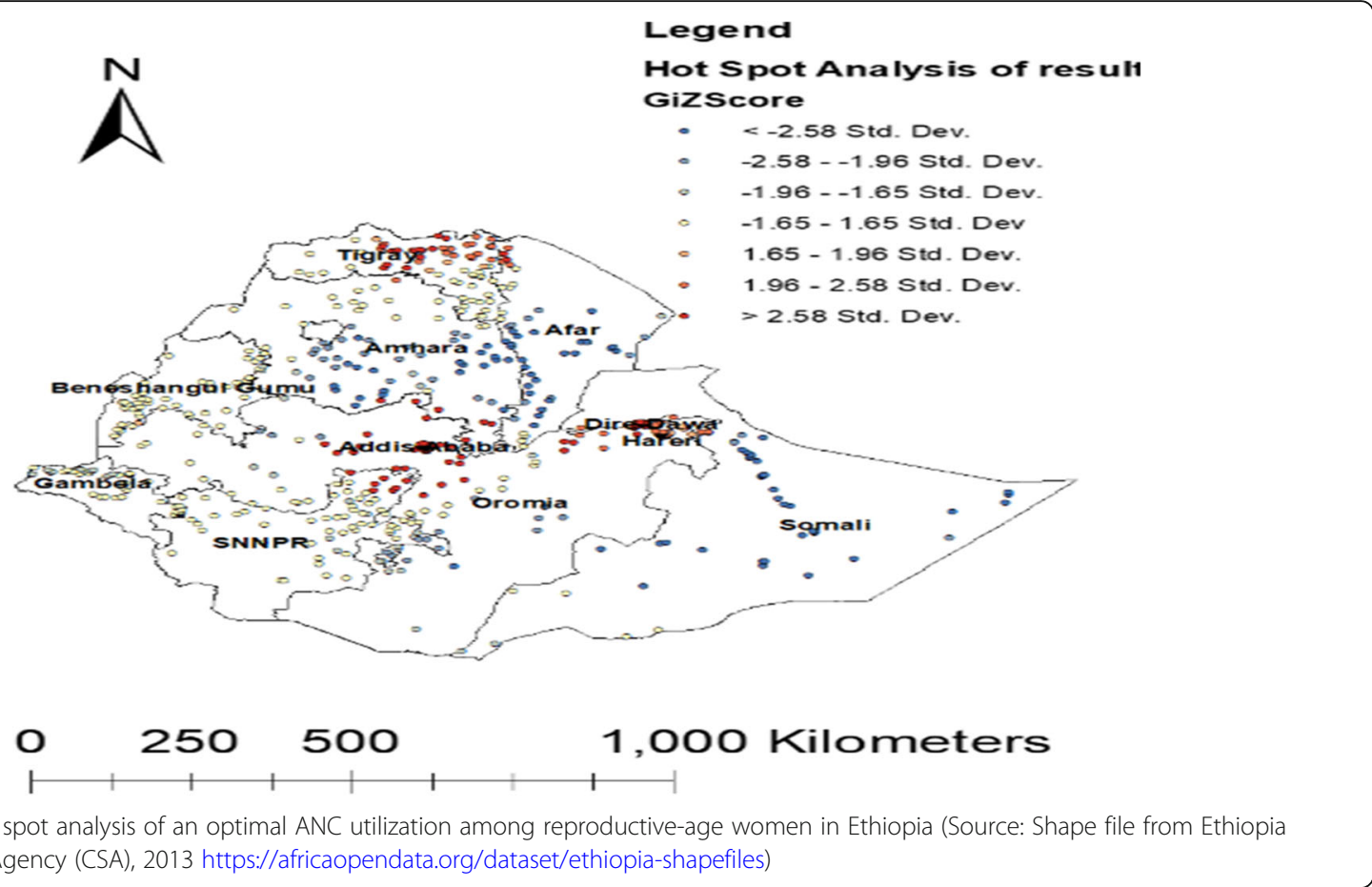

\section{Spatial SaTScan analysis of an optimal ANC visit Bernoulli based model}

Most likely primary clusters (means areas who had high an Optimal ANC visits) and secondary clusters (high an Optimal ANC visits but relatively less than pimary clusters) of an optimal ANC visits were identified. About 111 (priary and secondary) significant clusters were identified. Of which, 55 of them were most likely (primary) clusters and 56 were secondary clusters.

The primary cluster's spatial window was located in the west Benishangul, which was centered at $(8.883803 \mathrm{~N}$, 38.778503 E) / $21.03 \mathrm{~km}, \mathrm{RR}=2.94$ and Log-Likelihood ratio (LLR) of 145.88 at $p<0.001$. Women who live in the primary clusters increase an optimal ANC visits by three fold than women's outside the window (Table 2, Fig. 7).

\section{Determinants for an optimal ANC visit}

In the multivariate analysis, residence, religion, male partner's educational level, distance to the health institution, region, the timing of ANC,community-level literacy and community level service utilization were significantly associated with optimal ANC visit at p-value 0.05 .

The odds of optimal ANC utilization is reduced by $41 \%$ among rural women $(\mathrm{AOR}=0.59$, 95\% CI: $0.45-$ 0.77 ) as compared to women residing in urban areas. The odds of optimal ANC utilization is reduced by $29 \%$ for Protestants (AOR $=0.71,95 \% \mathrm{CI}: 0.55-0.91$ ) and $48 \%$ for Catholic \& traditional $(\mathrm{AOR}=0.52,95 \% \mathrm{CI}$ :
0.33-0.83) as compared to Orthodox Christian followers. Women, whose partners attain the secondary level of education, are 1.33 times $(\mathrm{AOR}=1.33,95 \% \mathrm{CI}$ : 1.05-1.67) more likely to have 4 ANC visits as compared to women who have a partner with no formal education. Women who reported that distance to a health institution is not a big problem are 1.21 times (AOR $=1.21,95 \% \mathrm{CI}: 1.04-1.39)$ more likely to have optimal ANC visits than their counterparts. Women who start ANC after 12 weeks of gestation are less likely to have adequate $\mathrm{ANC}$ visits $(\mathrm{AOR}=0.70$, 95\%CI: $0.60-$ $0.82)$ than those who start before 12 weeks of gestation. Pregnant women residing in regional states of Ethiopia are less likely to have optimal ANC visits, Tigray $(\mathrm{AOR}=0.48,95 \% \mathrm{CI}: 0.28-0.82)$, Afar $\quad(\mathrm{AOR}=0.13$, 95\%CI: 0.07-0.24), Amhara (AOR $=0.24$, 95\%CI: 0.140.42 ), Oromia (AOR $=0.25$, 95\%CI: 0.15-0.43), Somali $(\mathrm{AOR}=0.08,95 \% \mathrm{CI}: 0.05-0.15)$, Benishangul $(\mathrm{AOR}=$ 0.48, 95\%CI: 0.28-0.84), Southern Nations Nationalities and Peoples Region (SNNPR) $(\mathrm{AOR}=0.0 .48,95 \% \mathrm{CI}$ : 0.28-0.83), Gambela (AOR $=0.37$, 95\%CI: 0.21-0.66), Harari $\quad(\mathrm{AOR}=0.16, \quad 95 \% \mathrm{CI}: \quad 0.09-0.28)$, Diredawa (AOR $=0.52,95 \% \mathrm{CI}: 0.29-0.93)$, than women in the capital city, Addis Ababa. Women who live in a community where the distance to the health institution is not a big problem for a higher proportion of the women in the community are 1.28 times $(\mathrm{AOR}=0.128$, 95\%CI: 1.04-1.57) more likely to have optimal ANC visits (Table 3 ). 


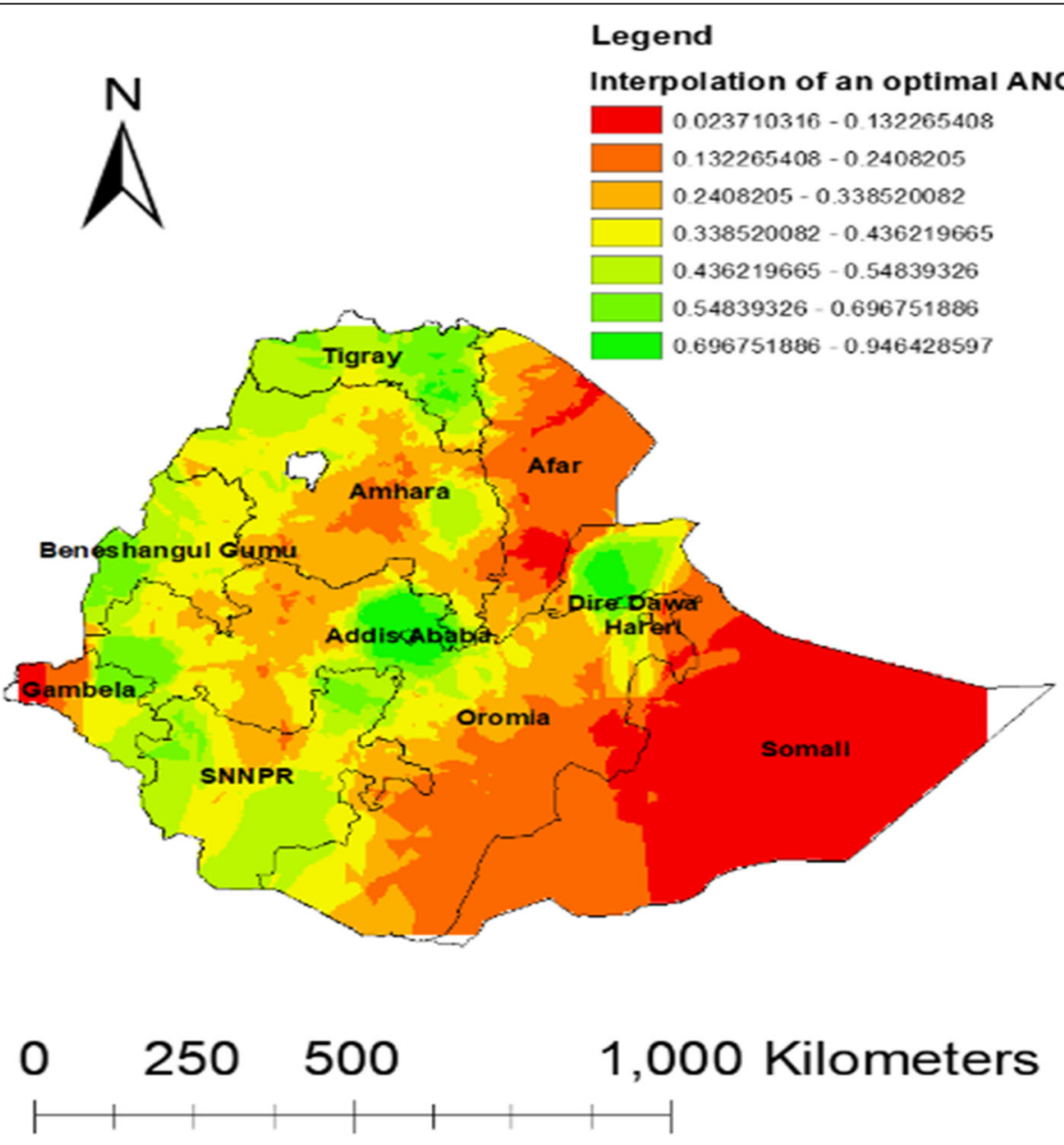

Fig. 6 Interpolation Optimal ANC visit in Ethiopia 2016 (Source: Shape file from Ethiopia Central Statistical Agency (CSA), 2013 https://africaopendata.org/dataset/ethiopia-shapefiles)

\section{Discussion}

The odds of optimal ANC utilization was reduced by $41 \%$ among rural women as compared to women residing in urban areas. This finding is supported by studies done in Indonesia [12], Nigeria [13], and Ethiopia [14]. This is due to the socioeconomic inequalities and differences in health services access between urban and rural areas in the country [15].

The odds of optimal ANC utilization is reduced by 29\% for Protestants and 48\% for Catholic and others as compared to Orthodox Christian followers. The effect of religion on maternal health service utilization is because it plays a significant role in shaping beliefs, norms, and values including those that relate to childbirth and health services use [16-18]. Reproductive health issues may also be considered as a subject not to be discussed easily between husband and wife in some religions [19].

Women, whose partners attain a secondary level of education, were 1.33 times more likely to have 4 ANC visits as compared to women who have a partner with no formal education. Similar findings were reported in studies conducted in Bangladesh [20], Debrebirhan central Ethiopia [21] and Metekel, western Ethiopia [22]. In Ethiopia, it is known that most women are socioeconomically dependent on male partners who are decisionmakers in households, and influence on maternal health care services utilization [23].

Women living in the regional states had lower odds of optimal ANC visits than women living in Addis Ababa. There was a significant difference in antenatal care utilization across the country regions. This finding is supported by a previous study conducted in Ethiopia [24]. Addis Ababa is the capital city of the country where health facilities are more accessible and women are more aware of maternal health services.

Distance to the health facilities was an important predictor for optimal ANC utilization. Women who reported distance to the health institution as not a big problem had $21 \%$ higher odds of optimal ANC visits than their counterparts. The finding is consistent with studies conducted in 
Table 2 SaTScan analysis of An optimal ANC visit among women in the last five years in Ethiopia, 2016

\begin{tabular}{|c|c|c|c|c|c|}
\hline Cluster & EA (enumeration Area) & Coordinate or Radi & RR & LLR & P-value \\
\hline Primary(55) & $\begin{array}{l}\begin{array}{l}236,252,83,353,475,261,539,451,61,225,264,110,302,293,330,159,19,211, \\
645,59,608,155,195,145,487,314,639,428,635,414,509,560,305,15,582,147 \\
100,108,247,31,107,626,153,170,402,369,339,91,11,532,464,144,90,287,463, \\
112\end{array}\end{array}$ & $\begin{array}{l}(8.883803 \mathrm{~N}, \\
38.778503 \mathrm{E}) / 21.03 \\
\mathrm{~km}\end{array}$ & 2.94 & 145.88 & $<0.001$ \\
\hline Secondary(56) & $\begin{array}{l}89,479,45,461,84,598,404,481,413,604,81,590,400,226,597,341,355,636,103 \\
129,117,192,156,584,196,181,430,579,263,623,528,134,255,99,298,575,551 \\
98,220,127,78,36294,237,550,605,340,235,538,384,424,188,583,585,268,421 \\
160\end{array}$ & $\begin{array}{l}(14.438634 \mathrm{~N}, \\
39.085800 \mathrm{E}) / 143.67 \\
\mathrm{~km}\end{array}$ & 1.91 & 60.98 & $<0.001$ \\
\hline
\end{tabular}

Indonesia [12], Uganda [18] and Tanzania [25]. These findings showed that the improvement of access to health services as well as the distribution of health services and especially in remote areas should be a priority.

This study revealed that the timing of the first ANC visit was significantly associated with the accomplishment of 4 ANC visits. Women who start their first visit after the 12 weeks of gestation are $70 \%$ less likely to have $4 \mathrm{ANC}$ visits. This is due to that women with delayed initiation of ANC may deliver before getting an adequate number of ANC visits. On the other hand, women who start ANC visit early, are more likely to have better awareness about the importance of the service and committed to attained consecutive visits.
In this study community-level factors like Community level literacy rate and community level ANC utilization rate were found to be important determinants for optimal ANC visit. Women from a community where there is a higher level of literacy and a high proportion of ANC utilization are more likely to have adequate ANC visits. This may be due to the herd effect of the community level behavior. Previous studies also suggest that community-level factors could lead to an increase in the utilization of maternal health care services [26, 27].

This study has strengths of nationally representative data, advanced statistical models were used to account correlations within clusters, and spatial analysis was used to indicate hotspot areas. However, this study has limitations of cross-sectional nature that may not show a true causal

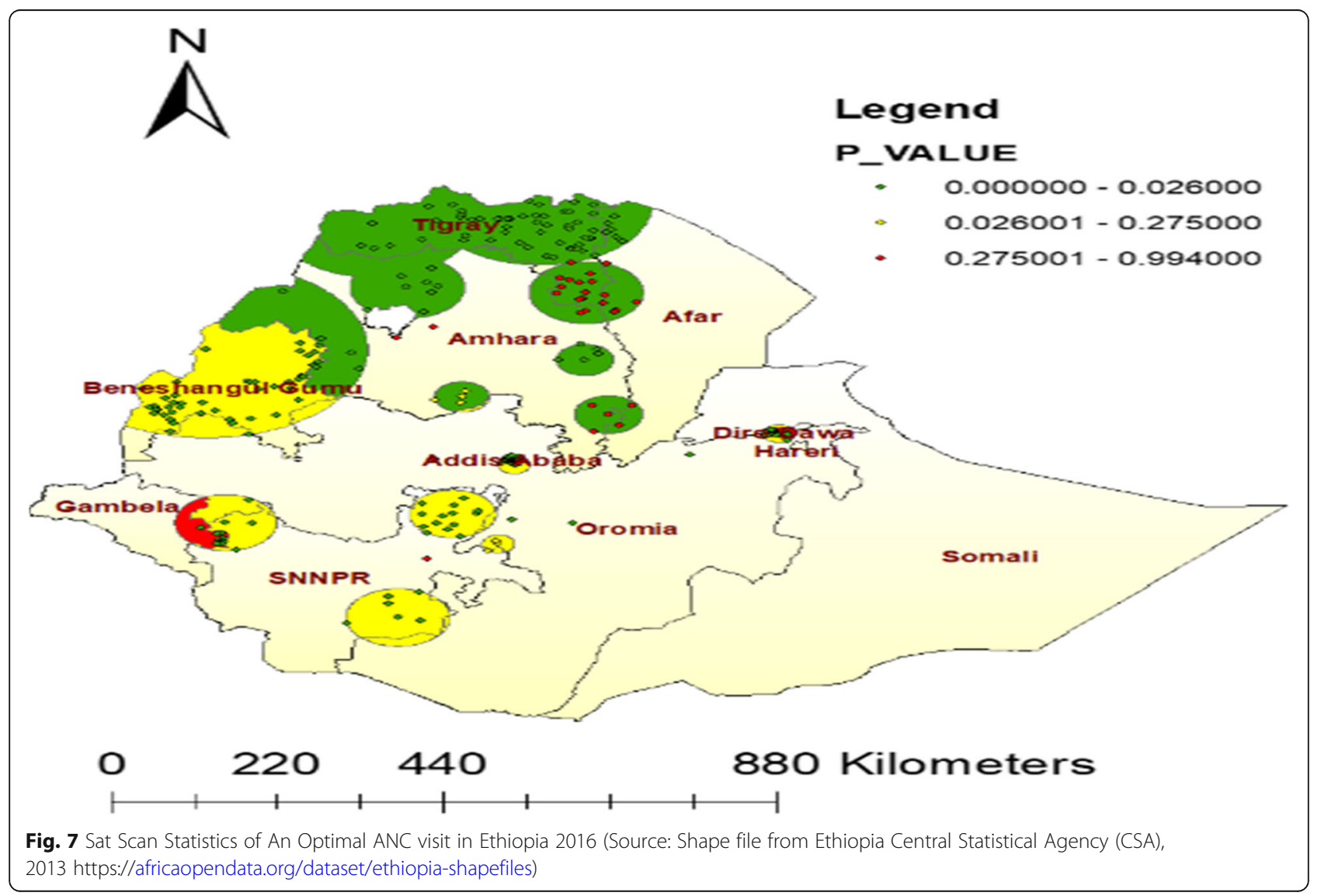


Table 3 Bi-variable and multi-variable odds ratio for potential factors of completing four or more ANC visit in Ethiopia, EDHS 2016

\begin{tabular}{|c|c|c|}
\hline Variables & COR(95\%Cl) & AOR(95\%Cl) \\
\hline \multicolumn{3}{|l|}{ Marital status } \\
\hline Never in union & ref & \\
\hline Currently in union & $0.99(0.97,1.03)$ & $0.95(0.91,1.00)$ \\
\hline \multicolumn{3}{|l|}{ Sex of household headed } \\
\hline Male & Ref & \\
\hline Female & $1.02(0.99,1.05)$ & $1.13(0.98,1.37)$ \\
\hline \multicolumn{3}{|l|}{ Place of Residence } \\
\hline Urban & Ref & \\
\hline Rural & $0.66(0.63,0.69)$ & $0.59(0.45,0.77)^{* *}$ \\
\hline \multicolumn{3}{|l|}{ Age } \\
\hline $15-19$ & Ref & Ref \\
\hline $20-24$ & $1.02(0.97,1.08)$ & $1.07(0.76,1.50)$ \\
\hline $25-29$ & $1.02(0.97,1.08)$ & $1.18(0.82,1.68)$ \\
\hline $30-34$ & $1.02(0.96,1.07)$ & $1.23(0.84,1.80)$ \\
\hline $35-39$ & $1.03(0.97,1.08)$ & $1.32(0.88,1.98)$ \\
\hline $40-44$ & $0.95(0.91,1.04)$ & $1.01(0.63,1.60)$ \\
\hline $45-49$ & $0.96(0.89,1.05)$ & $1.02(0.57,1.83)$ \\
\hline \multicolumn{3}{|l|}{ Religion } \\
\hline Orthodox & Ref & Ref \\
\hline Muslim & $0.52(0.44,0.62)$ & $1.03(0.82,1.28)$ \\
\hline Protestant & $0.60(0.49,0.73)$ & $0.71(0.55,0.91)^{*}$ \\
\hline Catholic \& traditional & $0.53(0.37,0.75)$ & $0.52(0.33,0.83)^{*}$ \\
\hline \multicolumn{3}{|l|}{ Birth order } \\
\hline 1 & Ref & \\
\hline $2-4$ & $0.96(0.93,0.98)$ & $0.88(0.71,1.09)$ \\
\hline$>=5$ & $0.93(0.91,0.96)$ & $0.85(0.62,1.17)$ \\
\hline \multicolumn{3}{|l|}{ Women Level of education } \\
\hline Unable to read and write & Ref & \\
\hline Primary education & $1.05(1.02,1.07)$ & $0.96(0.82,1.13)$ \\
\hline Secondary education & $1.16(1.11,1.21)$ & $1.02(0.77,1.35)$ \\
\hline Higher education & $1.23(1.16,1.31)$ & $1.02(0.67,1.56)$ \\
\hline \multicolumn{3}{|l|}{ Parity } \\
\hline 1 & Ref & Ref \\
\hline $2-5$ & $0.80(0.72,0.89)$ & $0.92(0.75,1.14)$ \\
\hline$\geq 5$ & $0.74(0.65,0.83)$ & $0.94(0.68,1.29)$ \\
\hline \multicolumn{3}{|l|}{ Wealth quartile } \\
\hline Poor & Ref & \\
\hline middle & $1.04(1.01,1.07)$ & $1.09(0.91,1.31)$ \\
\hline rich & $1.17(1.14,1.21)$ & $1.10(0.91,1.33)$ \\
\hline \multicolumn{3}{|c|}{ Distance to the health institution } \\
\hline Not a big problem & ref & ref \\
\hline A big problem & $1.44(1.30,1.59)$ & $1.21(1.04,1.39)^{*}$ \\
\hline \multicolumn{3}{|l|}{ Exposure to media } \\
\hline Yes & Ref & Ref \\
\hline
\end{tabular}


Table 3 Bi-variable and multi-variable odds ratio for potential factors of completing four or more ANC visit in Ethiopia, EDHS 2016 (Continued)

\begin{tabular}{|c|c|c|}
\hline Variables & COR $(95 \% \mathrm{Cl})$ & AOR(95\%Cl) \\
\hline No & $1.55(1.39,1.72)$ & $1.09(0.94,1.28)$ \\
\hline \multicolumn{3}{|l|}{ Partner's level of education } \\
\hline no education & Ref & ref \\
\hline Primary & $1.19(1.07,1.33)$ & $1.06(0.92,1.22)$ \\
\hline Secondary & $1.81(1.53,2.14)$ & $1.33(1.05,1.67)$ \\
\hline Higher & $1.69(1.40,2.05)$ & $1.02(0.76,1.36)$ \\
\hline \multicolumn{3}{|l|}{ Region } \\
\hline Tigray & $0.73(0.67,0.79)$ & $0.48(0.28,0.82)^{*}$ \\
\hline Afar & $0.48(0.44,0.52)$ & $0.13(0.07,0.24)^{*}$ \\
\hline Amhara & $0.56(0.51,0.61)$ & $0.24(0.14,0.42)^{*}$ \\
\hline Oromia & $0.52(0.48,0.56)$ & $0.25(0.15,0.43)^{*}$ \\
\hline Somalia & $0.45(0.42,0.49)$ & $0.08(0.05,0.15)^{*}$ \\
\hline Benishangul Gumuz & $0.62(0.57,0.68)$ & $0.48(0.28,0.84)^{*}$ \\
\hline SNNP & $0.61(0.56,0.66)$ & $0.48(0.28,0.83)^{*}$ \\
\hline Gambela & $0.59(0.54,0.64)$ & $0.37(0.21,0.66)^{*}$ \\
\hline Harari & $0.60(0.55,0.56)$ & $0.16(0.09,0.28)^{*}$ \\
\hline Addis Ababa & Ref & Ref \\
\hline Dire Dawa & $0.80(0.71,0.88)$ & $0.52(0.29,0.93)^{*}$ \\
\hline \multicolumn{3}{|c|}{ Community level ANC utilization } \\
\hline high & Ref & Ref \\
\hline low & $1.54(1.49,1.59)$ & $2.67(2.21,3.24)^{*}$ \\
\hline \multicolumn{3}{|l|}{ Community level literacy } \\
\hline low & Ref & Ref \\
\hline high & $1.38(1.32,1.43)$ & $1.07(1.03,1.12)^{*}$ \\
\hline \multicolumn{3}{|c|}{ Community level media exposure } \\
\hline Higher media exposure & Ref & Ref \\
\hline Lower media exposure & $1.50(1.05,1.75)$ & $1.16(0.95,1.42)$ \\
\hline \multicolumn{3}{|l|}{ Timing of ANC } \\
\hline Less than 12 weeks & Ref & Ref \\
\hline More than 12 weeks & $0.80(0.58,0.90)$ & $0.70(0.60,0.82)$ \\
\hline
\end{tabular}

Ref indicated reference category

*indicated significant at $5 \%$ level of significant

relationship. In addition, the effects of the health system and health worker factors were not assessed.

\section{Conclusion}

In this study, we have identified both individual-level and community-level factors, which determine the accomplishment of four ANC visits for pregnant women (an optimal ANC visit), and its spatial distribution. Women who lived in peripheral regions and rural areas, far from health institutions, start ANC after the 12 weeks of gestation and with a lower level of husband's education were less likely to complete four ANC visits. Whereas, women who were in a community where there are higher-level community level literacy and community level service utilizations were more likely to have adequate ANC visits. Therefore, interventions should focus on the involvement of male partners and at the community level for improving antenatal care utilization and better health outcomes and special attention should be given to regions like Somalia, Afar, and Gambella where a proportion of an Optimal ANC visit is low.

\section{Abbreviations}

ANC: Antenatal Care Visit; AOR: Adjusted Odds Ratio; Cl: Confidence Interval; EDHS: Ethiopia Demographic and Health Survey; GEE: Generalized Estimating Eqs.; IR: Individual Records; SNNP: Southern Nation and Nationalities of People of Ethiopia 


\section{Acknowledgments}

We would like to thank the Ethiopian Central Statistics Agency for providing us with all the relevant secondary data used in this study. Finally, we would like to thank all who directly or indirectly supported us.

\section{Authors' contributions}

ZTT and YA conceived the study, involved in the study design, data analysis, drafted the manuscript and critically reviewed the manuscript. All authors read and approved the final manuscript.

\section{Funding}

We did not receive external funds for this research.

\section{Availability of data and materials}

The datasets used and/or analysed during the current study are available from the corresponding author on reasonable request.

\section{Ethics approval and consent to participate}

Ethical clearance was obtained from measure DHS through filling requesting form for accessing data. The data used in this study are publicly available at www.measuredhs.com. Aggregated secondary data, which has not any personal identifying information that can be linked to study participants. The confidentiality of data was maintained anonymously.

\section{Consent for publication}

Not applicable.

\section{Competing interests}

The authors declared that they have no competing interests.

Received: 23 September 2019 Accepted: 7 February 2020

Published online: 04 March 2020

\section{References}

1. USAID. Ending Preventable Maternal Mortality:USAID Maternal Health Vision for Action Evidence for Strategic Approaches. 2015.

2. Carroli G, Villar J, Piaggio G, Khan-Neelofur D, Gülmezoglu M, Mugford M, et al. WHO systematic review of randomised controlled trials of routine antenatal care. Lancet. 2001;357(9268):1565-70.

3. Campbell OM, Graham WJ. Group LMSSs. Strategies for reducing maternal mortality: getting on with what works. Lancet. 2006;368(9543):1284-99.

4. Kuhnt J, Vollmer S. Antenatal care services and its implications for vital and health outcomes of children: evidence from 193 surveys in 69 low-income and middle-income countries. BMJ Open. 2017;7(11).

5. World Helath Organization. WHO recommendations on antenatal care for a positive pregnancy experience. 2016.

6. World Health Organization. WHO Antenatal Care Randomized Trail: Manual for the Implementation of the New Model. Geneva: 2002

7. Dowswell T, Carroli G, Duley L, Gates S, Gulmezoglu AM, Khan-Neelofur D, et al. Alternative versus standard packages of antenatal care for low-risk pregnancy. Cochrane Database Syst Rev. 2010;(10):Cd000934.

8. Ayoola AB. Reducing the number of antenatal care visits in low-risk pregnancies increases perinatal mortality in low- and middle-income countries; women in all settings prefer the standard visit schedule. Evid Based Nurs. 2011;14(2):55-6.

9. UNICEF. Monitoring the situation of children and women. 2018

10. Central statistical Agency. POPULATION and HOUSING CENSUS OF ETHIOPIA 2007.

11. Central statistical Agency. Ethiopian Demographic and Health Survey. 2016.

12. Titaley CR, Dibley MJ, Roberts CL. Factors associated with underutilization of antenatal care services in Indonesia: results of Indonesia demographic and health survey 2002/2003 and 2007. BMC Public Health. 2010;10:485.

13. Adewuyi EO, Auta A, Khanal V, Bamidele OD, Akuoko CP, Adefemi K, et al. Prevalence and factors associated with underutilization of antenatal care services in Nigeria: a comparative study of rural and urban residences based on the 2013 Nigeria demographic and health survey. PLoS One. 2018;13(5):e0197324.

14. Tiruaynet K, Muchie KF. Determinants of utilization of antenatal care services in Benishangul Gumuz region, Western Ethiopia: a study based on demographic and health survey. BMC Pregnancy Childbirth. 2019;19(1):115.

15. Gebre E, Worku A, Bukola F. Inequities in maternal health services utilization in Ethiopia 2000-2016: magnitude, trends, and determinants. Reprod Health. 2018;15(1):119.
16. Amooti-Kaguna B, Nuwaha F. Factors influencing choice of delivery sites in Rakai district of Uganda. Soc Sci Med (1982). 2000;50(2):203-13.

17. Chorongo D, Okinda FM, Kariuki EJ, Mulewa E, Ibinda F, Muhula S, et al. Factors influencing the utilization of focused antenatal care services in Malindi and Magarini sub-counties of Kilifi county, Kenya. Pan Afr Med J. 2016;25(Suppl 2):14

18. Kawungezi PC, AkiiBua D, Aleni C, Chitayi M, Niwaha A, Kazibwe A, et al. Attendance and utilization of antenatal care (ANC) services: multi-center study in upcountry areas of Uganda. Open J Prev Med. 2015;5(3):132-42.

19. Mekonnen $Y$, Mekonnen A. Factors influencing the use of maternal healthcare services in Ethiopia. J Health Popul Nutr. 2003;21(4):374-82.

20. Ali N, Sultana M, Sheikh N, Akram R, Mahumud RA, Asaduzzaman M, et al. Predictors of optimal antenatal care service utilization among adolescents and adult women in Bangladesh. Health Serv Res Managerial Epidemiol. 2018:5:2333392818781729

21. Shibre G, Mekonnen W. Socio-economic inequalities in ANC attendance among mothers who gave birth in the past 12 months in Debre Brehan town and surrounding rural areas, north East Ethiopia: a community-based survey. Reprod Health. 2019;16(1):99.

22. T G, Tura G, Mph. Antenatal Care Service Utilization and Associated Factors in Metekel Zone, Northwest Ethiopia. Ethiop J Health Sci. 2009;19(2).

23. Mohammed BH, Johnston JM, Vackova D, Hassen SM, Yi H. The role of male partner in utilization of maternal health care services in Ethiopia: a community-based couple study. BMC Pregnancy Childbirth. 2019;19(1):28.

24. Yeneneh A, Alemu K, Dadi AF, Alamirrew A. Spatial distribution of antenatal care utilization and associated factors in Ethiopia: evidence from Ethiopian demographic health surveys. BMC Pregnancy Childbirth. 2018;18(1):242.

25. Gupta S, Yamada G, Mpembeni R, Frumence G, Callaghan-Koru JA, Stevenson R, et al. Factors associated with four or more antenatal care visits and its decline among pregnant women in Tanzania between 1999 and 2010. PLoS One. 2014;9(7):e101893.

26. Yadav A, Kesarwani R. EFFECT OF INDIVIDUAL AND COMMUNITY FACTORS ON MATERNAL HEALTH CARE SERVICE USE IN INDIA: A MULTILEVEL APPROACH. J Biosoc Sci. 2016;48(1):1-19.

27. Chama-Chiliba CM, Koch SF. Utilization of focused antenatal care in Zambia: examining individual- and community-level factors using a multilevel analysis. Health Policy Plan. 2015;30(1):78-87.

\section{Publisher's Note}

Springer Nature remains neutral with regard to jurisdictional claims in published maps and institutional affiliations.

Ready to submit your research? Choose BMC and benefit from:

- fast, convenient online submission

- thorough peer review by experienced researchers in your field

- rapid publication on acceptance

- support for research data, including large and complex data types

- gold Open Access which fosters wider collaboration and increased citations

- maximum visibility for your research: over $100 \mathrm{M}$ website views per year

At $\mathrm{BMC}$, research is always in progress.

Learn more biomedcentral.com/submissions 